OPEN ACCESS

Edited by:

Kara Louise Britt,

Peter MacCallum

Cancer Centre, Australia

Reviewed by:

Tamara Louise Kalir,

Icahn School of Medicine

at Mount Sinai, USA

Anthony Ashton,

University of Sydney, Australia

*Correspondence:

Tiffany A. Katz

tiffany.katz@bcm.edu

Specialty section:

This article was submitted

to Women's Cancer,

a section of the journal

Frontiers in Oncology

Received: 09 July 2016 Accepted: 11 October 2016 Published: 26 October 2016

Citation:

Katz TA (2016) Potential Mechanisms underlying the Protective Effect of Pregnancy against Breast Cancer: A Focus on the IGF Pathway.

Front. Oncol. 6:228. doi: 10.3389/fonc.2016.00228

\section{Potential Mechanisms underlying the Protective Effect of Pregnancy against Breast Cancer: A Focus on the IGF Pathway}

\author{
Tiffany A. Katz* \\ Center for Precision Environmental Health, Baylor College of Medicine, Houston, TX, USA
}

A first full-term birth at an early age protects women against breast cancer by reducing lifetime risk by up to $50 \%$. The underlying mechanism resulting in this protective effect remains unclear, but many avenues have been investigated, including lobular differentiation, cell fate, and stromal composition. A single pregnancy at an early age protects women for 30-40 years, and this long-term protection is likely regulated by a relatively stable yet still modifiable method, such as epigenetic reprograming. Long-lasting epigenetic modifications have been shown to be induced by pregnancy and to target the IGF pathway. Understanding how an early first full-term pregnancy protects against breast cancer and the role of epigenetic reprograming of the IGF system may aid in developing new preventative strategies for young healthy women in the future.

Keywords: insulin-like growth factor I, pregnancy, mammary gland biology, breast cancer risk, breast cancer prevention

\section{INTRODUCTION}

An early first full-term birth (FFTB) is the most effective modifiable breast cancer prevention method, with the potential of reducing a woman's lifetime risk up to $50 \%$. The first documented observation of this preventative behavior was by Bernardino Ramazzini in 1700 . He noted that "tumors of the breast are found more often in nuns than any other women" and speculated that this was due to a life of celibacy (1). A landmark case-control study revisited this phenomenon in 1970, finding that compared to nulliparous women, women who underwent their FFTB before the age of 20 had a risk reduction of 50\%. In this study of 17,022 women (4323 cases and 12,699 controls) in 7 regions around the world, a strong positive linear relationship between age at FFTB and breast cancer risk was observed (2). Since then, others have reproduced these findings showing that women who experience their FFTB before the age of 20 or 25 reduce their lifetime risk by 50 or $38 \%$, respectively (3-5). An increased number of births is also associated with decreased breast cancer risk, and these associations are stronger for estrogen receptor (ER)+ disease (6-10).

The abovementioned study identified a positive linear correlation between age at FFTB and breast cancer risk (2). Nulliparous women were used as the reference group. Women who give birth for the first time above the age of 33 were no longer protected against breast cancer compared to nulliparous women. In fact, those women were now at an increased risk compared to nulliparous women. This is especially concerning since the average age at FFTB in the United States has been increasing over time (11). The proportion of women who gave birth for the first time between the ages of 30 and 34 
rose $28 \%$ (from 16.5 to $21.1 \%$ ) and those over 35 years of age rose $23 \%$ (from 7.4 to $9.1 \%$ ) between 2000 and 2014 (11). Learning more about the mechanism underlying the protective effect of an early FFTB against breast cancer could help to provide protection for women giving birth at an older age.

The protective effect of pregnancy has been replicated in multiple animal models including mice and rats using both carcinogen and spontaneous carcinoma models $(4,12,13)$. Simply replicating the hormonal milieu of pregnancy has been shown to induce robust protection against mammary tumors (14-16). Given at a dose resulting in circulating levels similar to pregnancy, estradiol (E2) alone decreases the percent of tumor bearing animals in response to a carcinogen; and E2 in combination with progesterone $(\mathrm{P} 4)$ enhances this protective effect presumably by creating an environment even more similar to a pregnant state $(14,15)$. Additionally, the parous mammary gland is less successful in supporting the development of hyperplastic lesions or tumors. In a syngeneic rat model, carcinogen-treated epithelial cells were transplanted into uniparous, age-matched virgin (AMV), or young virgin (YV) rats. Compared to either group of virgin rats, transplants into uniparous rats had fewer hyperplasias and adenocarcinomas (17).

The stage of the pregnancy cycle (i.e., pregnancy, lactation, or involution) most important in reducing breast cancer risk is unclear. The previously mentioned study (2) chose to include regions across the globe in order to capture women who breastfed for extended periods of time and women who rarely breast fed but was unable to confirm a link between breast feeding and breast cancer risk. Other studies have reported associations between breast feeding and breast cancer risk. In a meta-analysis of 31 studies, 27 included breast feeding data and 13 of those found that longer durations of breast feeding protected against breast cancer (18). The current recommendation by physicians is that breast feeding for longer than 2 years over a woman's lifetime is protective against breast cancer, and this is supported by multiple studies. Breast feeding for as little as 6 months (19) provides a significant reduction in breast cancer risk, but longer durations of breast feeding are even more beneficial (20-23).

Surprisingly, in a rodent model, lactation is not obligatory to elicit protection against mammary cancer. Parous rats that were not permitted to nurse and animals that did nurse were equally protected from mammary cancer (24). Additionally, the lactogenic drug perphenazine was not sufficient in protecting against mammary cancer (14).

\section{POTENTIAL MECHANISMS: LOBULAR DIFFERENTIATION, CELL FATE, AND STROMAL COMPOSITION}

\section{Lobular Differentiation}

In an attempt to identify the underlying cause of parity-induced protection against breast cancer, several morphogenic and molecular mechanisms have been investigated including differentiation state, cell fate, and stromal alterations of the mammary gland. One of the first comprehensive studies investigating differentiation of the breast reported that parous women displayed a higher proportion of differentiated lobules in the breast. Four lobule types were identified with type 1 being the least and type 4 being the most differentiated. Cells isolated from the least differentiated lobule type were the most susceptible to carcinogenic insults, displaying increased survival efficiency and multinucleation (25). Of peak importance, parous women who developed breast cancer displayed lobular profiles identical to nulliparous women. This indicates that these women may not have undergone the entire differentiation cycle required for the protective effect of parity against breast cancer (26-28).

Interestingly, in a more recent report, proportions of differentiated and undifferentiated lobules were not different between parous and nulliparous women (29). The two studies used distinct lobule identification techniques and sampling methods. The 2014 study used previously established imaging and quantitation criteria, described by Russo (26), and Milanese et al. (30), to determine the proportion of lobule types represented in each specimen. When comparing samples from nulliparous women and women $>10$ years postpartum $(n=10)$, there was no difference in lobular composition of the breast (29). The more recent study included women who underwent clinically indicated breast biopsies including only one specimen per sample, whereas the previously mentioned studies included whole breast or lumpectomy samples, which were divided several times providing numerous samplings per patient. These differences may have contributed to the discrepancy between studies.

It has been hypothesized that type 1 lobules in parous women may all appear histologically the same, but some may have regressed from a type 3 or 4 lobule and may actually be functionally and molecularly different from immature type 1 lobules in nulliparous women. This lobular regression has been termed age-related lobular involution. Studies investigating age-related lobular involution have found that women with predominately type 1 lobules and no type 3 lobules (i.e., lobular proportions similar to nulliparous women in the first study), have likely undergone lobular involution, and actually have a decreased risk for breast cancer $(30,31)$. These epidemiological data support the study by Jindal et al.; their finding may indicate that in women $>10$ years postpartum age-related involution may have occurred.

\section{Cell Fate}

While controversial, it is believed that changes in cell fate may contribute to the protective effect of pregnancy (32). Pregnancy modulates mammary stem cell number and function, but the long-term implications of these changes are unclear (33). Basal stem cells and alveolar progenitor cells populate the gland in preparation for lactation $(34,35)$. Shifts in these populations of cells could contribute to the protective effect of parity against breast cancer (36), but this is not a consistent finding $(12,37)$. Pathways involved in cell fate (wnt/notch) have been shown to be significantly altered with parity in both rodent models and women. In a murine gene expression array study, wnt 2 was downregulated in the mouse involuted mammary gland compared to nulliparous controls (38). Additionally, the ligand wnt 4 and the number of wnt4-secreting cells were dramatically reduced 
in parous mammary glands compared to nulliparous $(39,40)$. Of additional importance, wnt 4 is lower in breast tissue from parous women who also display a reduction in $\mathrm{CD} 44^{+} \mathrm{p} 27^{+}$cells (41). p27 is known to affect the number and proliferation of stem cells and may therefore indicate a reduction in the number of mammary progenitor cells in parous breast tissue.

\section{Stromal Composition}

Dramatic alterations in the parous stromal microenvironment have been well documented. The tissue microenvironment is extremely plastic in the breast especially during pregnancy. At this time, there is a great proliferative effort in the epithelial compartment, while the adipose cells are reduced and acini are formed. Acini begin producing and releasing milk, and the breast becomes engorged for lactation. During involution, the gland undergoes a dramatic reconstruction very similar to wound healing. During these stages, the gland becomes filled with activated fibroblasts and immune infiltration (42). These changes contribute to an enriched extracellular matrix (ECM), which becomes stiffer and more collagen dense with an increased stroma/parenchyma ratio $(38,43-46)$. Gene expression studies in rodents and humans have supported these findings showing that ECM and immune gene signatures can differentiate between parous and nulliparous breast tissue (47-49).

Of greater interest is the role these stromal alterations play in preventing tumorigenesis. In a syngeneic rat model, the postpartum epithelial structure was required for pseudopregnancy to protect the gland from breast cancer (50). In this study, epithelial cells were isolated from mice treated with a carcinogen and transplanted into parous animals, which either had their fat pad cleared prior to puberty or retained complete epithelial structures. Transplants into animals with a cleared fat pad displayed increased hyperplasia and carcinoma growth, while animals with full epithelial structure, which had been exposed to a pregnancy, were protected from carcinogenesis (50). In a similar study, mammary epithelial cells isolated from animals that were treated with a carcinogen were implanted into YVs, AMVs, and uniparous animals with cleared fat pads. Significantly fewer transplants grew in uniparous animals (14\%), compared to 33\% in AMV and 55\% in YV, and significantly fewer hyperplasias developed in the transplants in uniparous animals (17). These data indicate that both the presence of epithelial cells and the stromal status are important in determining outgrowth of tumorigenic cells.

The ECM composition has been shown to effect breast cancer cell growth (51-56). Particularly, the stiffness of the matrix can influence which signaling cascades become activated, as well as migration and cellular organization phenotypes. In response to prolactin, T47D cells in a high density/stiff matrix migrate less and signal through the FAK/ERK pathway, while in low density/ compliant matrix, they will migrate more but signal through the canonical JAK/STAT pathway (52). In a follow-up report, the interaction between E2 and prolactin was highly influenced by matrix stiffness (51). Since stromal composition and density are dramatically effected by parity, it is likely that these factors work together to influence the protective effect of parity against breast cancer.

\section{A ROLE FOR INSULIN-LIKE GROWTH FACTOR I IN THE PROTECTIVE EFFECT OF PREGNANCY: EPIDEMIOLOGICAL DATA AND RODENT MODELS}

\section{Epidemiological Data}

Insulin-like growth factor I (IGFI) in circulation has been shown in many studies to be associated with breast cancer risk (57-59). In a nested case-control study using the Nurses Health Study data, in premenopausal women, higher circulating IGFI was associated with a significant increase in breast cancer risk (60). Increased breast cancer risk was also associated with higher circulating IGFI measured during the first pregnancy (61). The Northern Sweden Maternity Cohort used a nested case-control design including 244 cases and 453 controls. In this study, circulating IGFI was higher in cases than controls and breast cancer risk increased significantly with higher IGFI tertiles. Compared to the lowest tertile, women in the highest IGFI tertile had a $73 \%$ increase in breast cancer risk (61). However, this was not replicated in two other studies: one using the AVON Longitudinal Study of Parents and Children Cohort (62) and another in the Finnish Maternity Cohort (63). Therefore, chronic exposure to high circulating IGFI may have a bigger impact than exposure to elevated levels during pregnancy.

While it is well accepted that circulating IGFI levels are associated with breast cancer risk, interestingly, parity is associated with lower circulating IGFI levels. In the Nurses Health Study, 1037 healthy women were used to investigate circulating IGFI and lifestyle factors. This study identified age, smoking, parity, and hormone use to be significantly associated with circulating IGFI levels (64). Circulating IGFI was significantly lower in parous women and was inversely correlated with number of births, which parallels the data on breast cancer risk and parity (64). These observations support the hypothesis that reduced IGFI postpartum contributes to the protective effect of pregnancy against breast cancer.

The Nurses Health Study data also show an inverse relationship between IGFI levels and age (64). This finding is indicative of the gradual decline of the growth hormone (GH)/IGF axis with age eventually leading to somatopause $(65,66)$. This is particularly interesting since the highest level of protection against breast cancer occurs in women who encounter their FFTB at an early age, when circulating IGFI levels are highest. Parous women have lower levels of circulating IGFI; therefore, women who undergo parity at a young age would forgo exposure to excessive IGFI levels (Figure 1). Women who undergo their first pregnancy late in life will be exposed to higher circulating IGFI levels until after birth (Figure 1). This parallels the breast cancer risk data in that women who give birth later are also at higher risk for breast cancer.

A link has also been found between IGFI and lobular differentiation. The Nurses Health Studies I and II used 472 women with benign breast disease in a cross-sectional design to show that higher circulating IGFI or a higher IGF:IGFBP3 ratio was associated with decreased odds of having predominantly type 1 lobules (67). Type 1 lobules are the most undifferentiated lobule 


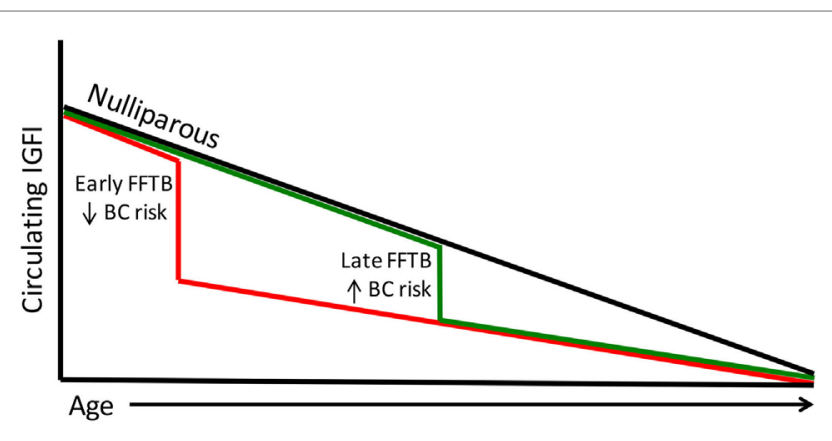

FIGURE 1 | Circulating IGFI levels parallel breast cancer risk. Circulating IGFI levels are lower in parous women compared to nulliparous women (black line). A FFTB at an early age (red line) reduces IGFI sooner, foregoing the excess circulating IGFI that women who become pregnant for the first time later encounter (green line). This parallels the data on breast cancer risk, with women who undergo a late FFTB displaying an increased breast cancer risk compared to those who undergo an early FFTB.

type as described previously, or possibly represent involuted lobules as speculated by Baer et al. Findings by Russo et al. show that having predominantly type 1 lobules is similar to a nulliparous breast architecture and increases risk for breast cancer (26-28), but other studies show that having predominately type 1 lobules (possibly involuted type 1 lobules) reduces risk for breast cancer $(30,31)$. While conflicting, these data together suggest a role for IGFI in lobular breast development and cancer risk. It is possible that IGFI contributes breast cancer risk partially by influencing differentiation or involution of breast lobules.

The relationship between IGFI and pregnancy is modified in women afflicted with gestational diabetes and preeclampsia, although the data are conflicting. One study reported an inverse association between IGFI or IGFBP1 and risk for gestational diabetes (68); another reported a positive association between IGFI or IGFBP3 and risk for gestational diabetes (69). While several studies show a lack of a correlation between IGFI and/or IGFBP1 or IGFBP3 and preeclampsia (70-72), the majority report lower IGFI in women with preeclampsia (73-75). Other studies found that higher IGFI is circulating prior to preeclampsia and in gestational hypertension $(76,77)$. Additionally, data on IGFBPs and preeclampsia vary; Ingec and Giudice report higher IGFBP1 in preeclampsia $(70,73)$, while Ning and Hietala report lower IGFBP1 in preeclampsia $(75,78)$. Interestingly, a longitudinal study looking over the course of pregnancy found that compared to healthy controls, during early gestation, IGFBP1 levels were lower in women who later developed preeclampsia, but in late gestation, BP1 levels were higher than controls (79). This observation could be converse for IGFI, in that IGFI could first be higher prior to the clinical condition of preeclampsia [as suggested above $(76,77)]$ and subsequently reduced with the clinically diagnosed preeclampsia (as the majority of the above studies report).

These findings beg the question whether pregnancy disorders have associations with breast cancer risk. Again, the data are conflicting with many papers finding no association between gestational diabetes or preeclampsia with breast cancer risk (80-84). In some reports, glucose intolerance or gestational diabetes was associated with an increase in breast cancer risk $(85,86)$, while others found a decrease in risk for breast cancer. One study found that patients with gestational diabetes display lower risk for premenopausal breast cancer (87). In patients with preeclampsia and pregnancy hypertension, a slightly lower breast cancer risk was reported (88), and the second study found substantially lower breast cancer risk in women with severe preeclampsia if they had their first child after the age of 30 (89). Again, the data are conflicting, but there could be multiple important considerations when assessing breast cancer risk, including timing of pregnancy, severity of the disorder during pregnancy, and changes in hormone levels over the course of pregnancy. All of these have yet to be directly tested.

In conclusion, long-term exposure to excessive IGFI in circulation leads to an increase in breast cancer risk as described above, and parous women display lower circulating IGFI and breast cancer risk indicating that IGFI contributes to the effect of parity on lifetime breast cancer risk (Figure 2). On the other hand, short-term changes in circulating IGFI during complicated pregnancies (those experiencing preeclampsia or gestational diabetes) may have less of an effect on future risk for breast cancer, as studies investigating IGF levels during these complications are conflicting as are those investigating breast cancer risk. If women who have experienced these complications do in fact have a lower risk for breast cancer than healthy parous controls, it may be through a mechanism unrelated to IGFI or occurring in a specific subset of women.

\section{Rodent Models}

Gene expression studies have shown that growth and proliferation pathways are reduced in parous animals and women. Several studies found IGF1 expression to be decreased with parity (48, 90-92). In a rodent model, circulating GH was reduced in parous animals leading to a reduction in mammary gland activation of the IGF/GH axis $(13,93)$. Two rat strains, Sprague Dawley and Wister Furth, were bred at 53 days of age and cannulated at 122 days of age to assess circulating GH. In both strains, average, as well as peak circulating $\mathrm{GH}$, were significantly reduced in parous animals. The reduction in circulating $\mathrm{GH}$ translated to reduced activation of $\mathrm{GH}$ signaling cascades in the mammary gland, specifically, phosphorylated Jak2, Stat5A, and Akt (93).

Circulating levels of GH as well as IGFI are obligatory for tumor development in certain rodent models. Rats with a genetic deletion of GH1 (spontaneous dwarf rats, SDR) are completely resistant to carcinogen-induced tumors $(94,95)$. These animals also display reduced circulating IGFI, and IGFI or GH supplementation rescues carcinogen-induced tumorigenesis (96). In the SDR model, parity or administering E2 and P4 protects against carcinogen-induced GH stimulated tumorigenesis dramatically, reducing tumor incidence from $100 \%$ ( $\mathrm{GH}$ alone) to $16.7 \%$ $(\mathrm{GH}+\mathrm{E} 2+\mathrm{P} 4)$ and increasing latency from 57 to 138 days, respectively (97). IGFI also abolished the protective effect of pregnancy. Nulliparous and parous animals were treated with IGFI or vehicle for 60 days beginning 7 days prior to carcinogen exposure. Parous animals displayed 16\% tumor incidence compared to AMVs displaying 100\% tumor incidence. Further, treating parous animals with IGFI resulted in an $83 \%$ tumor 

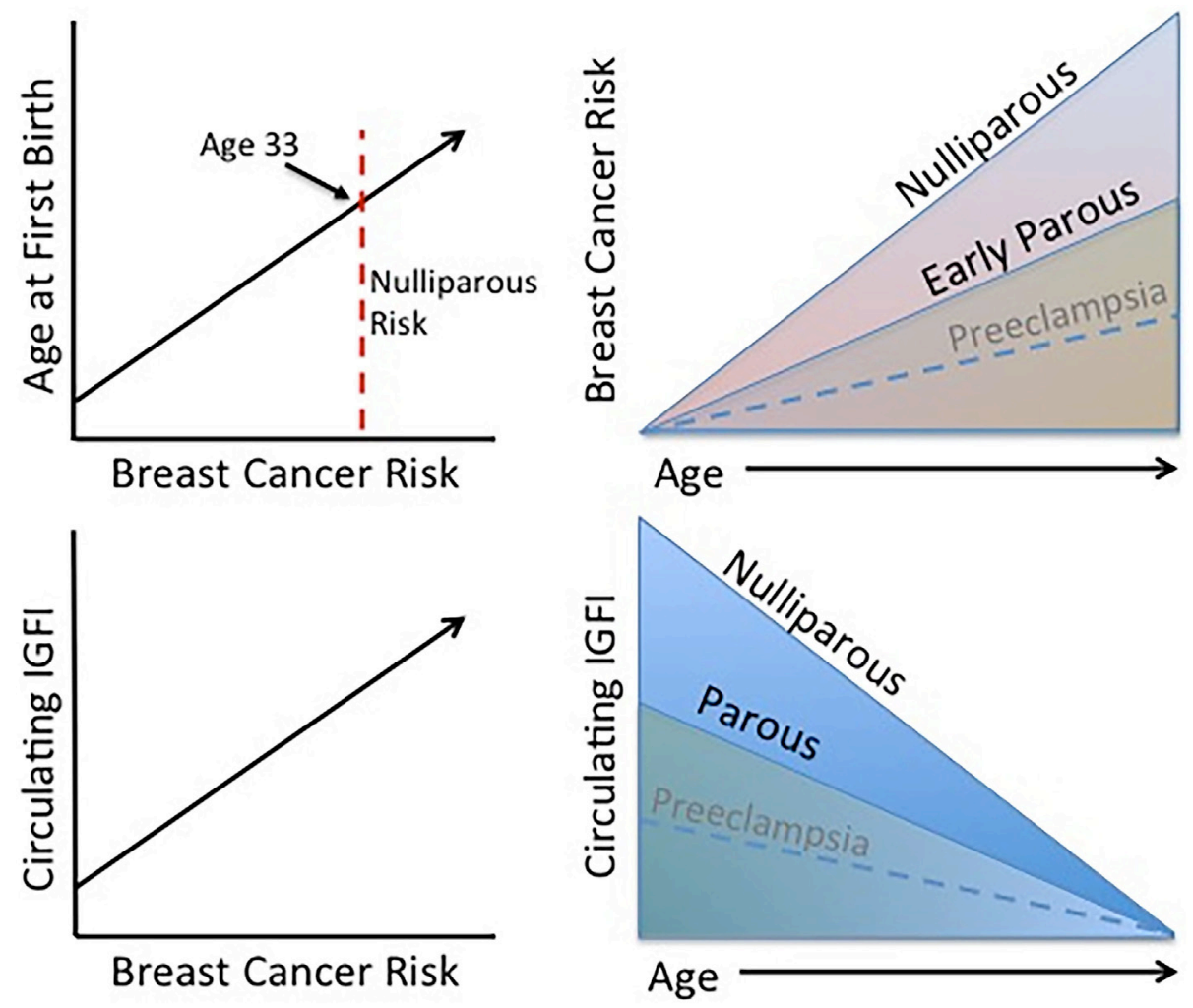

FIGURE 2 | Established trends associated with the protective effect of pregnancy. Age at FFTB is positively correlated with breast cancer risk. Women who experience an early parity benefit from a long-term protection against breast cancer compared to nulliparous women. Interestingly, higher levels of circulating IGFI are also positively associated with breast cancer risk and parous women display lower circulating IGFI levels. Although less firmly established, preeclampsia may be associated with a lower breast cancer risk as well as circulating IGFI levels.

incidence, thereby eliminating the protective effect of parity (96). IGFI treatment also prevented the induction of lactalbumin in the mammary gland, indicating that full differentiation was not achieved in these animals. These data support the hypothesis that reduced mammary gland differentiation increases tumor susceptibility (96).

\section{PREGNANCY REPROGRAMS THE EPIGENOME, POTENTIALLY CONTRIBUTING TO THE PROTECTIVE EFFECT AGAINST BREAST CANCER}

Epigenetic changes play a major role in mammary growth and differentiation. DNA is dramatically hypomethylated during lactation to open chromatin and allow expression of milk protein genes (98). A recent study investigating the effect of parity on DNA methylation used MeDIP to pull down methylated regions genome-wide and conducted next-generation sequencing in 19 parous and 16 nulliparous women. They identified FOXA1 to be hypermethylated and silenced with parity. Since FOXA1 is known to colocalize with ER at enhancers, they believe the silencing of FOXA1 will effect ER action, ultimately leading to changes that contribute to the protective effect of parity against breast cancer.
This study also found the IGF acid labile subunit (IGFALS), a protein responsible for transport of IGFI in circulation, to be hypomethylated with parity. If this hypomethylation leads to a change in ALS levels in circulation, this could alter the effects of IGFI on target tissues, also contributing to the protective effect of parity.

In our recent study, we identified the Igf1r to be hypermethylated and silenced in parous mammary glands. We harvested mammary glands from parous mice and AMVs immediately postpartum (early) and 6 months postpartum (late) (99). This study design enabled us to identify parity-induced differences in DNA methylation, which persist long after pregnancy, therefore possibly contributing to the lifelong protective effect of pregnancy. We utilized a novel targeted hybridization-based approach to identify differentially methylated regions (DMRs). Hybridization probes were designed by Agilent to target regions of the genome likely to be regulated by DNA methylation, covering 3.7 million $\mathrm{CpG}$ cites in $\mathrm{CpG}$ islands, shores, promoters, enhancers, introns, exons, and intergenic regions. Our analysis identified 624 hypermethylated and 322 hypomethylated genes, which were discovered in the early time point and persisted into the late time point. The Igflr was in the top 10 persistently differentially methylated genes. The DMR in the Igf1r was located in intron 2, the largest intron in the gene. This DMR consisted of 


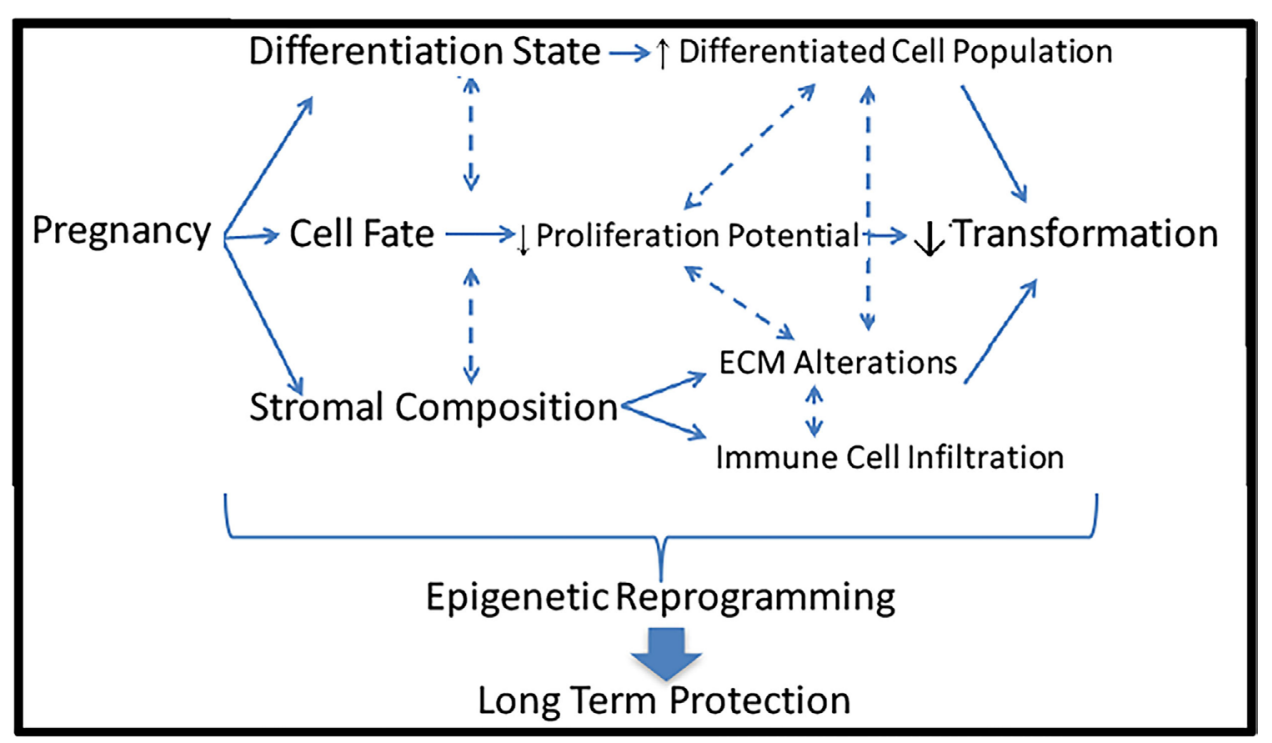

FIGURE 3 | Potential mechanisms underlying the protective effect of pregnancy against breast cancer. Pregnancy induces a multitude of dramatic changes in the breast including differentiation state, cell fate, and stromal composition. Each of these alterations could lead to reduced risk of cellular transformation and breast cancer induction. All of these mechanisms could be controlled by epigenetic reprograming, leading to long-term protective effects.

five CpG sites, all of which displayed increased DNA methylation with parity. Igflr gene expression was significantly reduced at the late time point demonstrating the long-lasting reprograming effect at this locus. We also looked at other IGF pathway members and found several to be significantly hypermethylated at the late time point including the ligands Igf1, Igfbp4, Irs 1, Prlr, and Stat5b. Additionally interesting is that these regions of differential DNA methylation also aligned with regions regulated by histone modifications as evidenced by in silico analysis in the UCSC genome browser. When aligning the DMR in the Igf1 $r$ with several histone marks, peaks in $\mathrm{H} 3 \mathrm{~K} 4 \mathrm{me} 1$ and $\mathrm{H} 3 \mathrm{~K} 4 \mathrm{me} 3$ overlap with this portion of intron 2 . The same was true for $\operatorname{Irs} 1, \operatorname{Ig} f 1$, and $\operatorname{Igfbp} 4$, each aligning with multiple histone marks. These results show that pregnancy induces long-lasting reprograming of the epigenome by altering DNA methylation and possibly histone modifications. These alterations affect the IGF pathway and may contribute to the protective effect of parity.

As previously mentioned, histone modifications are also likely to play a role in reprograming the breast epigenome during pregnancy. In the breasts of nulliparous women, nuclei were large and euchromatic in contrast to parous women displaying small heterochromatic nuclei with strong methylation of histones at repressive marks $\mathrm{H} 3 \mathrm{~K} 9 \mathrm{me} 2$ and $\mathrm{H} 3 \mathrm{~K} 27 \mathrm{me} 3$ (100). One study identified $\mathrm{H} 3 \mathrm{~K} 27 \mathrm{me} 3$ and its writer EZH2 to be increased during pregnancy and to decline during late pregnancy, particularly in the mammary stem cell population. This regulation was tightly correlated with gene expression of pregnancy-associated targets such as Csn2 and Wap and was mediated by P4 (101).

\section{CONCLUSION AND FUTURE DIRECTIONS}

Investigations probing the mechanism underlying the protective effect of pregnancy against breast cancer have been conducted in many areas including lobular differentiation, cell fate, and stromal composition. However, no single cause has been identified, and likely these mechanisms complexly interact to elicit the protective effect. The long-lasting effect of an early FFTB on reducing breast cancer risk implies that a relatively persistent modification may contribute to this phenomenon such as epigenetic reprograming (Figure 3).

While an early FFTB provides the greatest protection against breast cancer compared to any other risk factor, a method to exploit this phenomenon for a preventative strategy has not been developed. Currently, the most widely used preventative measure is tamoxifen, but due to toxicities, this is only available to highrisk women. Tamoxifen therapy causes unpleasant side effects leading to a drastic diminishment in its use in more recent years $(102,103)$. There are investigations into IGF1R inhibitors as preventative therapies, but these are toxic as well and therefore again only will be helpful in high-risk women (104-106). With the age of FFTB rising and the lack of preventative options, discovering the most important mechanisms underlying the protective effect of an early FFTB is imperative to developing prevention strategies for young healthy women $(11,107)$. The most effective way to eradicate a disease is through prevention; therefore, new preventative avenues for young healthy women are essential to reducing breast cancer incidence.

\section{AUTHOR CONTRIBUTIONS}

TK conducted literature searches and wrote the review article.

\section{FUNDING}

This work was funded by the National Institutes of Health under P30ES02351, R01ES023206, and U01ES026719. 


\section{REFERENCES}

1. Mustacchi P. Ramazzini and Rigoni-Stern on parity and breast cancer. Clinical impression and statistical corroboration. Arch Intern Med (1961) 108:639-42. doi:10.1001/archinte.1961.03620100131018

2. MacMahon B, Cole P, Lin TM, Lowe CR, Mirra AP, Ravnihar B, et al. Age at first birth and breast cancer risk. Bull World Health Organ (1970) 43:209-21.

3. Li CI, Malone KE, Porter PL, Lawton TJ, Voigt LF, Cushing-Haugen KL, et al. Relationship between menopausal hormone therapy and risk of ductal, lobular, and ductal-lobular breast carcinomas. Cancer Epidemiol Biomarkers Prev (2008) 17:43-50. doi:10.1158/1055-9965.EPI-07-0558

4. Medina D, Smith GH. Chemical carcinogen-induced tumorigenesis in parous, involuted mouse mammary glands. J Natl Cancer Inst (1999) 91:967-9. doi:10.1093/jnci/91.11.967

5. Schonfeld SJ, Pfeiffer RM, Lacey JV Jr, Berrington de Gonzalez A, Doody MM, Greenlee RT, et al. Hormone-related risk factors and postmenopausal breast cancer among nulliparous versus parous women: an aggregated study. Am J Epidemiol (2011) 173:509-17. doi:10.1093/aje/kwq404

6. Hinkula M, Pukkala E, Kyyronen P, Kauppila A. Grand multiparity and the risk of breast cancer: population-based study in Finland. Cancer Causes Control (2001) 12:491-500. doi:10.1023/A:1011253527605

7. Ma H, Henderson KD, Sullivan-Halley J, Duan L, Marshall SF, Ursin G, et al. Pregnancy-related factors and the risk of breast carcinoma in situ and invasive breast cancer among postmenopausal women in the California Teachers Study cohort. Breast Cancer Res (2010) 12:R35. doi:10.1186/bcr2589

8. Phipps AI, Buist DS, Malone KE, Barlow WE, Porter PL, Kerlikowske K, et al. Reproductive history and risk of three breast cancer subtypes defined by three biomarkers. Cancer Causes Control (2011) 22:399-405. doi:10.1007/ s10552-010-9709-0

9. Britt K, Ashworth A, Smalley M. Pregnancy and the risk of breast cancer. Endocr Relat Cancer (2007) 14:907-33. doi:10.1677/ERC-07-0137

10. Yuasa S, MacMahon B. Lactation and reproductive histories of breast cancer patients in Tokyo, Japan. Bull World Health Organ (1970) 42:195-204.

11. Mathews TJ, Hamilton BE. Mean age of mothers is on the rise: United States, 2000-2014. NCHS Data Brief (2016) 232:1-8.

12. Raafat A, Strizzi L, Lashin K, Ginsburg E, McCurdy D, Salomon D, et al. Effects of age and parity on mammary gland lesions and progenitor cells in the FVB/N-RC mice. PLoS One (2012) 7:e43624. doi:10.1371/journal. pone. 0043624

13. Thordarson G, Jin E, Guzman RC, Swanson SM, Nandi S, Talamantes F. Refractoriness to mammary tumorigenesis in parous rats: is it caused by persistent changes in the hormonal environment or permanent biochemical alterations in the mammary epithelia? Carcinogenesis (1995) 16:2847-53. doi:10.1093/carcin/16.11.2847

14. Guzman RC, Yang J, Rajkumar L, Thordarson G, Chen X, Nandi S. Hormonal prevention of breast cancer: mimicking the protective effect of pregnancy. Proc Natl Acad Sci U S A (1999) 96:2520-5. doi:10.1073/pnas.96.5.2520

15. Rajkumar L, Guzman RC, Yang J, Thordarson G, Talamantes F, Nandi S. Short-term exposure to pregnancy levels of estrogen prevents mammary carcinogenesis. Proc Natl Acad Sci U S A (2001) 98:11755-9. doi:10.1073/ pnas. 201393798

16. Sivaraman L, Stephens LC, Markaverich BM, Clark JA, Krnacik S, Conneely OM, et al. Hormone-induced refractoriness to mammary carcinogenesis in Wistar-Furth rats. Carcinogenesis (1998) 19:1573-81. doi:10.1093/ carcin/19.9.1573

17. Abrams TJ, Guzman RC, Swanson SM, Thordarson G, Talamantes F, Nandi S. Changes in the parous rat mammary gland environment are involved in parity-associated protection against mammary carcinogenesis. Anticancer Res (1998) 18:4115-21.

18. Yang L, Jacobsen KH. A systematic review of the association between breastfeeding and breast cancer. J Womens Health (Larchmt) (2008) 17:1635-45. doi:10.1089/jwh.2008.0917

19. Gonzalez-Jimenez E, Garcia PA, Aguilar MJ, Padilla CA, Alvarez J. Breastfeeding and the prevention of breast cancer: a retrospective review of clinical histories. J Clin Nurs (2014) 23:2397-403. doi:10.1111/jocn.12368

20. Awatef M, Olfa G, Imed H, Kacem M, Imen C, Rim C, et al. Breastfeeding reduces breast cancer risk: a case-control study in Tunisia. Cancer Causes Control (2010) 21:393-7. doi:10.1007/s10552-009-9471-3
21. Li CI, Malone KE, Porter PL, Weiss NS, Tang MT, Daling JR. Reproductive and anthropometric factors in relation to the risk of lobular and ductal breast carcinoma among women 65-79 years of age. Int J Cancer (2003) 107:647-51. doi:10.1002/ijc.11465

22. Yuan JM, Yu MC, Ross RK, Gao YT, Henderson BE. Risk factors for breast cancer in Chinese women in Shanghai. Cancer Res (1988) 48:1949-53.

23. Zheng T, Holford TR, Mayne ST, Owens PH, Zhang Y, Zhang B, et al. Lactation and breast cancer risk: a case-control study in Connecticut. $\mathrm{Br}$ J Cancer (2001) 84:1472-6. doi:10.1054/bjoc.2001.1793

24. Russo J, Russo IH. Susceptibility of the mammary gland to carcinogenesis. II. Pregnancy interruption as a risk factor in tumor incidence. Am J Pathol (1980) 100:497-512.

25. Russo J, Reina D, Frederick J, Russo IH. Expression of phenotypical changes by human breast epithelial cells treated with carcinogens in vitro. Cancer Res (1988) 48:2837-57.

26. Russo J, Rivera R, Russo IH. Influence of age and parity on the development of the human breast. Breast Cancer Res Treat (1992) 23:211-8. doi:10.1007/ BF01833517

27. Russo J, Romero AL, Russo IH. Architectural pattern of the normal and cancerous breast under the influence of parity. Cancer Epidemiol Biomarkers Prev (1994) 3:219-24.

28. Russo J, Russo IH. Toward a physiological approach to breast cancer prevention. Cancer Epidemiol Biomarkers Prev (1994) 3:353-64.

29. Jindal S, Gao D, Bell P, Albrektsen G, Edgerton SM, Ambrosone CB, et al. Postpartum breast involution reveals regression of secretory lobules mediated by tissue-remodeling. Breast Cancer Res (2014) 16:R31. doi:10.1186/ bcr3633

30. Milanese TR, Hartmann LC, Sellers TA, Frost MH, Vierkant RA, Maloney SD, et al. Age-related lobular involution and risk of breast cancer. J Natl Cancer Inst (2006) 98:1600-7. doi:10.1093/jnci/djj439

31. Baer HJ, Collins LC, Connolly JL, Colditz GA, Schnitt SJ, Tamimi RM. Lobule type and subsequent breast cancer risk: results from the Nurses' Health Studies. Cancer (2009) 115:1404-11. doi:10.1002/cncr.24167

32. Medina D. Mammary developmental fate and breast cancer risk. Endocr Relat Cancer (2005) 12:483-95. doi:10.1677/erc.1.00804

33. Asselin-Labat ML, Vaillant F, Sheridan JM, Pal B, Wu D, Simpson ER, et al. Control of mammary stem cell function by steroid hormone signalling. Nature (2010) 465:798-802. doi:10.1038/nature09027

34. Boulanger CA, Wagner KU, Smith GH. Parity-induced mouse mammary epithelial cells are pluripotent, self-renewing and sensitive to TGF-beta1 expression. Oncogene (2005) 24:552-60. doi:10.1038/sj.onc.1208185

35. Van Keymeulen A, Rocha AS, Ousset M, Beck B, Bouvencourt G, Rock J, et al. Distinct stem cells contribute to mammary gland development and maintenance. Nature (2011) 479:189-93. doi:10.1038/nature10573

36. Siwko SK, Dong J, Lewis MT, Liu H, Hilsenbeck SG, Li Y. Evidence that an early pregnancy causes a persistent decrease in the number of functional mammary epithelial stem cells - implications for pregnancy-induced protection against breast cancer. Stem Cells (2008) 26:3205-9. doi:10.1634/ stemcells.2008-0103

37. Britt KL, Kendrick H, Regan JL, Molyneux G, Magnay FA, Ashworth A, et al. Pregnancy in the mature adult mouse does not alter the proportion of mammary epithelial stem/progenitor cells. Breast Cancer Res (2009) 11:R20. doi:10.1186/bcr2245

38. Misra Y, Bentley PA, Bond JP, Tighe S, Hunter T, Zhao FQ. Mammary gland morphological and gene expression changes underlying pregnancy protection of breast cancer tumorigenesis. Physiol Genomics (2012) 44:76-88. doi:10.1152/physiolgenomics.00056.2011

39. Meier-Abt F, Bentires-Alj M. How pregnancy at early age protects against breast cancer. Trends Mol Med (2014) 20:143-53. doi:10.1016/j. molmed.2013.11.002

40. Meier-Abt F, Milani E, Roloff T, Brinkhaus H, Duss S, Meyer DS, et al. Parity induces differentiation and reduces Wnt/Notch signaling ratio and proliferation potential of basal stem/progenitor cells isolated from mouse mammary epithelium. Breast Cancer Res (2013) 15:R36. doi:10.1186/bcr3419

41. Choudhury S, Almendro V, Merino VF, Wu Z, Maruyama R, Su Y, et al. Molecular profiling of human mammary gland links breast cancer risk to a p27(+) cell population with progenitor characteristics. Cell Stem Cell (2013) 13:117-30. doi:10.1016/j.stem.2013.05.004 
42. Zhao W, Grubbs CJ, Myers RK, Nilsen-Hamilton M. Parity is associated with an expanded macrophage population in the mammary gland. Int J Oncol (2010) 37:1195-202. doi:10.3892/ijo_00000771

43. Maller O, Hansen KC, Lyons TR, Acerbi I, Weaver VM, Prekeris R, et al. Collagen architecture in pregnancy-induced protection from breast cancer. J Cell Sci (2013) 126:4108-10. doi:10.1242/jcs.121590

44. Ferguson DJ, Anderson TJ. A morphological study of the changes which occur during pregnancy in the human breast. Virchows Arch A Pathol Anat Histopathol (1983) 401:163-75. doi:10.1007/BF00692642

45. Russo J, Russo IH. Biological and molecular bases of mammary carcinogenesis. Lab Invest (1987) 57:112-37.

46. Russo J, Tay LK, Russo IH. Differentiation of the mammary gland and susceptibility to carcinogenesis. Breast Cancer Res Treat (1982) 2:5-73. doi:10.1007/ BF01805718

47. Asztalos S, Gann PH, Hayes MK, Nonn L, Beam CA, Dai Y, et al. Gene expression patterns in the human breast after pregnancy. Cancer Prev Res (Phila) (2010) 3:301-11. doi:10.1158/1940-6207.CAPR-09-0069

48. Blakely CM, Stoddard AJ, Belka GK, Dugan KD, Notarfrancesco KL, Moody $\mathrm{SE}$, et al. Hormone-induced protection against mammary tumorigenesis is conserved in multiple rat strains and identifies a core gene expression signature induced by pregnancy. Cancer Res (2006) 66:6421-31. doi:10.1158/00085472.CAN-05-4235

49. Rotunno M, Sun X, Figueroa J, Sherman ME, Garcia-Closas M, Meltzer P, et al. Parity-related molecular signatures and breast cancer subtypes by estrogen receptor status. Breast Cancer Res (2014) 16:R74. doi:10.1186/ bcr3689

50. Martins FC, Botelho MF, Cabrita AM, de Oliveira CF. Influence of normal mammary epithelium on breast cancer progression: the protective role of early pregnancy. Tumori (2010) 96:999-1003.

51. Barcus CE, Holt EC, Keely PJ, Eliceiri KW, Schuler LA. Dense collagen-I matrices enhance pro-tumorigenic estrogen-prolactin crosstalk in MCF-7 and T47D breast cancer cells. PLoS One (2015) 10:e0116891. doi:10.1371/ journal.pone. 0116891

52. Barcus CE, Keely PJ, Eliceiri KW, Schuler LA. Stiff collagen matrices increase tumorigenic prolactin signaling in breast cancer cells. J Biol Chem (2013) 288:12722-32. doi:10.1074/jbc.M112.447631

53. Bemis LT, Schedin P. Reproductive state of rat mammary gland stroma modulates human breast cancer cell migration and invasion. Cancer Res (2000) 60:3414-8.

54. Harvell DM, Kim J, O’Brien J, Tan AC, Borges VF, Schedin P, et al. Genomic signatures of pregnancy-associated breast cancer epithelia and stroma and their regulation by estrogens and progesterone. Horm Cancer (2013) 4:140-53. doi:10.1007/s12672-013-0136-z

55. Schedin P, Keely PJ. Mammary gland ECM remodeling, stiffness, and mechanosignaling in normal development and tumor progression. Cold Spring Harb Perspect Biol (2011) 3:a003228. doi:10.1101/cshperspect.a003228

56. Schedin P, O'Brien J, Rudolph M, Stein T, Borges V. Microenvironment of the involuting mammary gland mediates mammary cancer progression. J Mammary Gland Biol Neoplasia (2007) 12:71-82. doi:10.1007/ s10911-007-9039-3

57. Schernhammer ES, Holly JM, Pollak MN, Hankinson SE. Circulating levels of insulin-like growth factors, their binding proteins, and breast cancer risk. Cancer Epidemiol Biomarkers Prev (2005) 14:699-704. doi:10.1158/10559965.EPI-04-0561

58. Wu MH, Chou YC, Chou WY, Hsu GC, Chu CH, Yu CP, et al. Relationships between critical period of estrogen exposure and circulating levels of insulin-like growth factor-I (IGF-I) in breast cancer: evidence from a case-control study. Int J Cancer (2010) 126:508-14. doi:10.1002/ijc.24722

59. Endogenous Hormones and Breast Cancer Collaborative Group; Key TJ, Appleby PN, Reeves GK, Roddam AW. Insulin-like growth factor 1 (IGF1), IGF binding protein 3 (IGFBP3), and breast cancer risk: pooled individual data analysis of 17 prospective studies. Lancet Oncol (2010) 11:530-42. doi:10.1016/S1470-2045(10)70095-4

60. Hankinson SE, Willett WC, Colditz GA, Hunter DJ, Michaud DS, Deroo B, et al. Circulating concentrations of insulin-like growth factor-I and risk of breast cancer. Lancet (1998) 351:1393-6. doi:10.1016/S0140-6736(97) 10384-1

61. Chen T, Lukanova A, Grankvist K, Zeleniuch-Jacquotte A, Wulff M, Johansson R, et al. IGF-I during primiparous pregnancy and maternal risk of breast cancer. Breast Cancer Res Treat (2010) 121:169-75. doi:10.1007/ s10549-009-0519-6

62. Jeffreys M, Northstone K, Holly J, Emmett P, Gunnell D. Levels of insulin-like growth factor during pregnancy and maternal cancer risk: a nested case-control study. Cancer Causes Control (2011) 22:945-53. doi:10.1007/ s10552-011-9767-y

63. Toriola AT, Lundin E, Schock H, Grankvist K, Pukkala E, Chen T, et al. Circulating insulin-like growth factor-I in pregnancy and maternal risk of breast cancer. Cancer Epidemiol Biomarkers Prev (2011) 20:1798-801. doi:10.1158/1055-9965.EPI-11-0441

64. Holmes MD, Pollak MN, Hankinson SE. Lifestyle correlates of plasma insulin-like growth factor I and insulin-like growth factor binding protein 3 concentrations. Cancer Epidemiol Biomarkers Prev (2002) 11:862-7.

65. Junnila RK, List EO, Berryman DE, Murrey JW, Kopchick JJ. The GH/ IGF-1 axis in ageing and longevity. Nat Rev Endocrinol (2013) 9:366-76. doi:10.1038/nrendo.2013.67

66. Lamberts SW, van den Beld AW, van der Lely AJ. The endocrinology of aging. Science (1997) 278:419-24. doi:10.1126/science.278.5337.419

67. Rice MS, Tamimi RM, Connolly JL, Collins LC, Shen D, Pollak MN, et al. Insulin-like growth factor-1, insulin-like growth factor binding protein-3 and lobule type in the Nurses' Health Study II. Breast Cancer Res (2012) 14:R44. doi: $10.1186 / \mathrm{bcr} 3141$

68. Qiu C, Vadachkoria S, Meryman L, Frederick IO, Williams MA. Maternal plasma concentrations of IGF-1, IGFBP-1, and C-peptide in early pregnancy and subsequent risk of gestational diabetes mellitus. Am J Obstet Gynecol (2005) 193:1691-7. doi:10.1016/j.ajog.2005.04.015

69. Zhu Y, Mendola P, Albert PS, Bao W, Hinkle SN, Tsai MY, et al. Insulin-like growth factor axis and gestational diabetes: a longitudinal study in a multiracial cohort. Diabetes (2016). doi:10.2337/db16-0514

70. Giudice LC, Martina NA, Crystal RA, Tazuke S, Druzin M. Insulin-like growth factor binding protein-1 at the maternal-fetal interface and insulin-like growth factor-I, insulin-like growth factor-II, and insulin-like growth factor binding protein-1 in the circulation of women with severe preeclampsia. Am J Obstet Gynecol (1997) 176:751-7. doi:10.1016/S0002-9378 (97)70598-2

71. Hubinette A, Lichtenstein P, Brismar K, Vatten L, Jacobsen G, Ekbom A, et al. Serum insulin-like growth factors in normal pregnancy and in pregnancies complicated by preeclampsia. Acta Obstet Gynecol Scand (2003) 82:1004-9. doi:10.1034/j.1600-0412.2003.00034.x

72. Vatten LJ, Nilsen TI, Juul A, Jeansson S, Jenum PA, Eskild A. Changes in circulating level of IGF-I and IGF-binding protein-1 from the first to second trimester as predictors of preeclampsia. Eur J Endocrinol (2008) 158:101-5. doi:10.1530/EJE-07-0386

73. Ingec M, Gursoy HG, Yildiz L, Kumtepe Y, Kadanali S. Serum levels of insulin, IGF-1, and IGFBP-1 in pre-eclampsia and eclampsia. Int J Gynaecol Obstet (2004) 84:214-9. doi:10.1016/S0020-7292(03)00342-4

74. Kocyigit Y, Bayhan G, Atamer A, Atamer Y. Serum levels of leptin, insulin-like growth factor-I and insulin-like growth factor binding protein-3 in women with pre-eclampsia, and their relationship to insulin resistance. Gynecol Endocrinol (2004) 18:341-8. doi:10.1080/09513590410001704975

75. Ning Y, Williams MA, Vadachkoria S, Muy-Rivera M, Frederick IO, Luthy DA. Maternal plasma concentrations of insulinlike growth factor-1 and insulinlike growth factor-binding protein-1 in early pregnancy and subsequent risk of preeclampsia. Clin Biochem (2004) 37:968-73. doi:10.1016/j. clinbiochem.2004.07.009

76. Bartha JL, Romero-Carmona R, Torrejon-Cardoso R, Comino-Delgado R. Insulin, insulin-like growth factor-1, and insulin resistance in women with pregnancy-induced hypertension. Am J Obstet Gynecol (2002) 187:735-40. doi:10.1067/mob.2002.126283

77. Grobman WA, Kazer RR. Serum insulin, insulin-like growth factor-I, and insulin-like growth factor binding protein-1 in women who develop preeclampsia.Obstet Gynecol(2001)97:521-6.doi:10.1097/00006250-20010400000008

78. Hietala R, Pohja-Nylander P, Rutanen EM, Laatikainen T. Serum insulin-like growth factor binding protein-1 at 16 weeks and subsequent preeclampsia. Obstet Gynecol (2000) 95:185-9. doi:10.1016/S0029-7844(99)00489-5

79. Anim-Nyame N, Hills FA, Sooranna SR, Steer PJ, Johnson MR. A longitudinal study of maternal plasma insulin-like growth factor binding protein-1 concentrations during normal pregnancy and pregnancies 
complicated by pre-eclampsia. Hum Reprod (2000) 15:2215-9. doi:10.1093/ humrep/15.10.2215

80. Brasky TM, Li Y, Jaworowicz DJ Jr, Potischman N, Ambrosone CB, Hutson AD, et al. Pregnancy-related characteristics and breast cancer risk. Cancer Causes Control (2013) 24:1675-85. doi:10.1007/s10552-013-0242-9

81. Hanf V, Hanf D. Reproduction and breast cancer risk. Breast Care (Basel) (2014) 9:398-405. doi:10.1159/000369570

82. Hardefeldt PJ, Edirimanne S, Eslick GD. Diabetes increases the risk of breast cancer: a meta-analysis. Endocr Relat Cancer (2012) 19:793-803. doi:10.1530/ ERC-12-0242

83. Sella T, Chodick G, Barchana M, Heymann AD, Porath A, Kokia E, et al. Gestational diabetes and risk of incident primary cancer: a large historical cohort study in Israel. Cancer Causes Control (2011) 22:1513-20. doi:10.1007/ s10552-011-9825-5

84. Troisi R, Weiss HA, Hoover RN, Potischman N, Swanson CA, Brogan $\mathrm{DR}$, et al. Pregnancy characteristics and maternal risk of breast cancer. Epidemiology (1998) 9:641-7. doi:10.1097/00001648-199811000-00014

85. Dawson SI. Long-term risk of malignant neoplasm associated with gestational glucose intolerance. Cancer (2004) 100:149-55. doi:10.1002/cncr.20013

86. Perrin MC, Terry MB, Kleinhaus K, Deutsch L, Yanetz R, Tiram E, et al. Gestational diabetes and the risk of breast cancer among women in the Jerusalem Perinatal Study. Breast Cancer Res Treat (2008) 108:129-35. doi:10.1007/s10549-007-9585-9

87. Bejaimal SA, Wu CF, Lowe J, Feig DS, Shah BR, Lipscombe LL. Short-term risk of cancer among women with previous gestational diabetes: a population-based study. Diabet Med (2016) 33:39-46. doi:10.1111/dme.12796

88. Kim JS, Kang EJ, Woo OH, Park KH, Woo SU, Yang DS, et al. The relationship between preeclampsia, pregnancy-induced hypertension and maternal risk of breast cancer: a meta-analysis. Acta Oncol (2013) 52:1643-8. doi:10.3109/ 0284186X.2012.750033

89. Innes KE, Byers TE. First pregnancy characteristics and subsequent breast cancer risk among young women. Int J Cancer (2004) 112:306-11. doi:10.1002/ijc.20402

90. D'Cruz CM, Moody SE, Master SR, Hartman JL, Keiper EA, Imielinski MB, et al. Persistent parity-induced changes in growth factors, TGF-beta3, and differentiation in the rodent mammary gland. Mol Endocrinol (2002) 16:2034-51. doi:10.1210/me.2002-0073

91. Peri S, de Cicco RL, Santucci-Pereira J, Slifker M, Ross EA, Russo IH, et al. Defining the genomic signature of the parous breast. BMC Med Genomics (2012) 5:46. doi:10.1186/1755-8794-5-46

92. Santucci-Pereira J, George C, Armiss D, Russo IH, Vanegas JE, Sheriff F, et al. Mimicking pregnancy as a strategy for breast cancer prevention. Breast Cancer Manag (2013) 2:283-94. doi:10.2217/bmt.13.16

93. Dearth RK, Delgado DA, Hiney JK, Pathiraja T, Oesterreich S, Medina D, et al. Parity-induced decrease in systemic growth hormone alters mammary gland signaling: a potential role in pregnancy protection from breast cancer. Cancer Prev Res (Phila) (2010) 3:312-21. doi:10.1158/1940-6207.CAPR09-0074

94. Shen Q, Lantvit DD, Lin Q, Li Y, Christov K, Wang Z, et al. Advanced rat mammary cancers are growth hormone dependent. Endocrinology (2007) 148:4536-44. doi:10.1210/en.2007-0513

95. Swanson SM, Unterman TG. The growth hormone-deficient Spontaneous Dwarf rat is resistant to chemically induced mammary carcinogenesis. Carcinogenesis (2002) 23:977-82. doi:10.1093/carcin/23.6.977

96. Thordarson G, Slusher N, Leong H, Ochoa D, Rajkumar L, Guzman R, et al. Insulin-like growth factor (IGF)-I obliterates the pregnancy-associated protection against mammary carcinogenesis in rats: evidence that IGF-I enhances cancer progression through estrogen receptor-alpha activation via the mitogen-activated protein kinase pathway. Breast Cancer Res (2004) 6:R423-36. doi:10.1186/bcr812

97. Thordarson G, Semaan S, Low C, Ochoa D, Leong H, Rajkumar L, et al. Mammary tumorigenesis in growth hormone deficient spontaneous dwarf rats; effects of hormonal treatments. Breast Cancer Res Treat (2004) 87:277-90. doi:10.1007/s10549-004-9504-2

98. Rijnkels M, Kabotyanski E, Montazer-Torbati MB, Hue Beauvais C, Vassetzky Y, Rosen JM, et al. The epigenetic landscape of mammary gland development and functional differentiation. J Mammary Gland Biol Neoplasia (2010) 15:85-100. doi:10.1007/s10911-010-9170-4

99. Katz TA, Liao SG, Palmieri VJ, Dearth RK, Pathiraja TN, Huo Z, et al. Targeted DNA methylation screen in the mouse mammary genome reveals a parity-induced hypermethylation of Igf1r that persists long after parturition. Cancer Prev Res (Phila) (2015) 8:1000-9. doi:10.1158/1940-6207.CAPR-15-0178

100. Russo J, Santucci-Pereira J, de Cicco RL, Sheriff F, Russo PA, Peri S, et al. Pregnancy-induced chromatin remodeling in the breast of postmenopausal women. Int J Cancer (2012) 131:1059-70. doi:10.1002/ijc.27323

101. Pal B, Bouras T, Shi W, Vaillant F, Sheridan JM, Fu N, et al. Global changes in the mammary epigenome are induced by hormonal cues and coordinated by Ezh2. Cell Rep (2013) 3:411-26. doi:10.1016/j.celrep.2012.12.020

102. Freedman AN, Yu B, Gail MH, Costantino JP, Graubard BI, Vogel VG, et al. Benefit/risk assessment for breast cancer chemoprevention with raloxifene or tamoxifen for women age 50 years or older. J Clin Oncol (2011) 29:2327-33. doi:10.1200/JCO.2010.33.0258

103. Waters EA, Cronin KA, Graubard BI, Han PK, Freedman AN. Prevalence of tamoxifen use for breast cancer chemoprevention among U.S. women. Cancer Epidemiol Biomarkers Prev (2010) 19:443-6. doi:10.1158/1055-9965. EPI-09-0930

104. Kleinberg DL, Ameri P, Singh B. Pasireotide, an IGF-I action inhibitor, prevents growth hormone and estradiol-induced mammary hyperplasia. Pituitary (2011) 14:44-52. doi:10.1007/s11102-010-0257-0

105. Ruan W, Fahlbusch F, Clemmons DR, Monaco ME, Walden PD, Silva AP, et al. SOM230 inhibits insulin-like growth factor-I action in mammary gland development by pituitary independent mechanism: mediated through somatostatin subtype receptor 3? Mol Endocrinol (2006) 20:426-36. doi:10.1210/ me.2005-0283

106. Singh B, Smith JA, Axelrod DM, Ameri P, Levitt H, Danoff A, et al. Insulinlike growth factor-I inhibition with pasireotide decreases cell proliferation and increases apoptosis in pre-malignant lesions of the breast: a phase 1 proof of principle trial. Breast Cancer Res (2014) 16:463. doi:10.1186/ s13058-014-0463-1

107. Matthews TJ, Hamilton BE. First births to older women continue to rise. NCHS Data Brief (2014) 152:1-8.

Conflict of Interest Statement: The author declares that the research was conducted in the absence of any commercial or financial relationships that could be construed as a potential conflict of interest.

Copyright $\odot 2016 \mathrm{Katz}$. This is an open-access article distributed under the terms of the Creative Commons Attribution License (CC BY). The use, distribution or reproduction in other forums is permitted, provided the original author(s) or licensor are credited and that the original publication in this journal is cited, in accordance with accepted academic practice. No use, distribution or reproduction is permitted which does not comply with these terms. 